\title{
Cellulase Production by Native Bacteria Using Water Hyacinth as Substrate under Solid State Fermentation
}

\author{
Suresh Chandra Kurup, R. ${ }^{1}$, Snishamol, C. ${ }^{1}$ and Nagendra Prabhu, G. ${ }^{1 *}$ \\ ${ }^{1}$ Microbial Biotechnology Laboratory, P. G. Department of Zoology and Research Centre, \\ S. D. College, University of Kerala, Alleppey, 688003, Kerala, India \\ * Department of Biotechnology, Asian Institute of Medicine, Science and Technology, \\ Amanjaya Campus, 08000, Sungai Petani, Kedah Darul Aman, Malaysia \\ Email: nagendra_prabhu@aimst.edu.my, alp_prabhugn@sancharnet.in
}

\begin{abstract}
Most of the freshwater systems in tropical countries are infested with one kind of aquatic weed or the other causing serious environmental problems. All efforts to control the growth and spread of these weeds have failed miserably and hence the concept of "eradication through utilization" is being adopted by many researchers. Solid state fermentation, the culturing of microorganisms on moist solid substrates in the absence or near absence of free water, has generated great deal of interest among researchers because of its various advantages over the submerged fermentation technique. Cellulase enzyme is used extensively in various industries, especially in textile, food and in the bioconversion of lignocellulosic wastes to alcohol. The extensive use of cellulase in industries depends on the cost of the enzyme and hence considerable research is being carried out to isolate better microbial strains and also to develop new fermentation processes with the aim to reduce the product cost. The objective of the present study is to determine whether water hyacinth, one of the commonly found aquatic weeds, can be used as a substrate for cellulase production, by three native bacterial isolates named WHB 3, WHB 4 and SMB 3, under the process of solid state fermentation. Results indicate that all the three isolates produced cellulase enzyme by using water hyacinth as the solid support. Under optimized conditions of moisture, $\mathrm{pH}$, temperature, incubation time and inoculum concentration, the enzyme yield increased from 16.8 to 94.8 units for SMB 3, from 25.2 to 110.4 units for WHB 3 and from 18.0 to 127.2 units for WHB 4. The addition of nitrogen and carbon sources resulted in a significant increase in cellulase yield and WHB 3 produced the maximum amount of 216 units followed by SMB 3 and WHB 4.
\end{abstract}

Keywords: solid state fermentation, water hyacinth, cellulase

\section{INTRODUCTION}

Most of the tropical and sub-tropical countries are blessed with a variety of freshwater bodies like ponds, lakes, backwaters and canals, both natural and man-made. They play an important role in the cultural heritage and economic status of the nations. Now, due to a variety of reasons, most of these aquatic systems are infested with one kind of aquatic weed or the other. The most common ones include Eichhornia crassipes (water hyacinth), Salvinia molesta (water moss) and Pistia stratiotes (water lettuce). All these are non-endemic and were introduced to the tropical aquatic ecosystems during the $17^{\text {th }}$ and $18^{\text {th }}$ centuries through a variety of routes. As they were nonendemic, there are no natural control mechanisms such as insects and fishes that feed on them (Gopal, 1987). This factor, coupled with their fast growth rate and high capacity for survival has resulted in their rapid and unchecked growth filling up the entire water bodies. The present situation is mostly anthropogenic or man-made. A major portion of the fertilizers that are used for agriculture ultimately find its way into the nearby water bodies and cause eutrophication or nutrient enrichment, favouring the growth of these weeds. Indiscriminate dumping of

${ }^{*}$ Corresponding author domestic and industrial solid wastes to the canals and lakes also contribute to the problem (Gopal, 1987; Nagendra Prabhu, 2001).

Under favorable growth conditions, these weeds may double within about a week's time and their perennial, mat forming nature means that they cover the entire surface of the water. Excessive growth can result in complete coverage of water surfaces, which degrades natural habitats in several ways. Heavy growth of these aggressive weeds competes with and shades desirable native vegetation. Mats of floating plants prevent atmospheric oxygen from entering the water, while the decaying plants drop to the bottom, greatly consuming dissolved oxygen needed by fish and other aquatic life. This also prevents the entry of sunlight to the bottom layers, and slowly kills the natural, endemic flora and fauna. Their luxuriant growth prevents the natural flow of water in irrigation channels, obstructs smooth navigation in the waterways, and interferes with hydroelectric power generation. Disease spreading vector species of mosquitoes breed freely in the static waters. The decomposition of the dead plants results in obnoxious smell, decreases clarity of water and depletes the dissolved oxygen content of the water, making it unsuitable for human use. Animal habitat is most 
noticeably altered by the obliteration of open water. Migrating birds may not recognize or stop at water bodies covered with these weeds. Local fishermen have found it impossible to cast their nets into water covered with dense mats of Salvinia (Gopal, 1987; Harley, et. al., 1997; Calvert, 2002).

As the infestation of aquatic weeds in aquatic system produces serious environmental problems, they must be eradicated. But, all efforts to control the growth and spread of these weeds, including physical, chemical and biological methods have failed miserably or are too expensive to carry out on a regular basis. Hence the concept of "eradication through utilization" is being adopted by many countries and researchers are focusing on new methods of utilizing these "natural resources". (Nagendra Prabhu, 2001; Calvert, 2002).

Solid-state fermentation (SSF) refers to the growth of microorganisms on solid substrate (such as agricultural by-products) with little or no free water. SSF is an ancient technique which was abandoned in the U.S. around 1940 in favor of the more promising submerged or liquid fermentation. SSF had recently been experiencing renewed interest because there are many processes that are more productive and profitable in SSF over submerged liquid fermentation, for example the production of some enzymes. The success of SSF processes mainly depends on the type of the solid substrate used. In some cases, the substrate itself will provide the nutrients required for microbial growth and product formation (Nigam and Singh, 1996; Nagendra Prabhu \& Chandrasekaran, 1996; Tengerdy and Szakacs, 2003).

Cellulase refers to a family of enzymes which act in concert to hydrolyze cellulose. Cellulase is used extensively in the textile and food industries, bioconversion of lignocellulosic wastes to alcohol, animal feed industry as additive, isolation of plant protoplasts, in plant virus studies, metabolic investigations and genetic modification experiments (Evans and Bravo, 1983; Potrykus and Shillito, 1986; Bhat, 2000). The extensive use of cellulase in many industries depends on the cost of the enzyme which in turn depends on the method of production. Hence, research all over the world focuses on isolating new, hyper producing microbial strains and also to develop new fermentation processes aimed at reducing the cost of the enzyme with a view to bring down the overall process cost (Tengerdy, 1996; Villena et. al., 2001; Tengerdy and Szakacs, 2003).

Cellulolytic bacteria associated with the aquatic weeds of Kerala have been reported earlier by our group (Snishamol et. al., 2001, Suresh Chandra Kurup and Nagendra Prabhu, 2001). Here we report on the development of a solid state fermentation process aimed at producing cellulase enzyme, using water hyacinth as substrate using three of the selected isolates.

\section{MATERIALS AND METHODS}

\section{Microorganisms}

Three bacteria, namely SMB 3, WHB 3 and WHB 4 originally isolated from the decaying Eichhornia and Salvinia, collected from Alleppey, Kerala, India were used for the present study. Preliminary identification and partial characterization of the isolated bacterial cultures were done according to biochemical characterization studies based on Bergey's Manual of Systematic Bacteriology (Snishamol et. al. 2001; Suresh Chandra Kurup and Nagendra Prabhu, 2001). Species level identification was performed at the Microbial Type Culture Collection at the Institute of Microbial Technology, Chandigarh, India. They were maintained on CMC-Agar slants and were subcultured every month. Inoculum was prepared by growing the cells in Berg's medium containing CM-cellulose as inducer. The cells were harvested after 24 hours and resuspended in sterile saline. (Nagendra Prabhu, 1997; Nagendra Prabhu \& Chandrasekaran, 1996, 1997).

\section{Solid substrate and fermentation process}

Production of cellulase enzyme by selected isolates under solid state fermentation using water hyacinth as the substrate was carried out using standard techniques of solid state fermentation (Lonsane, 1994; Pandey et. al., 2001). The strategies developed by the author for bacterial enzyme production under solid state fermentation (Nagendra Prabhu, 1997, Nagendra Prabhu \& Chandrasekaran, 1995, 1996, 1997 \& 1999), were also adopted in the present study with slight modifications to suit the laboratory conditions.

Fresh water hyacinth (Eichhornia crassipes), collected from the nearby ponds and canals from Alleppey, Kerala, India was used as the solid substrate. 10 grams of chopped plants, taken in $250 \mathrm{ml}$ Erlenmeyer flasks and moistened with either distilled water with or without different carbon and nitrogen sources were used in all experiments. The flasks were autoclaved for 15 minutes, cooled to room temperature and inoculated with $2 \mathrm{ml}$ of the prepared inoculum. The flasks were then incubated for 24 hours at the desired temperature at 85$90 \%$ humidity in a humidity chamber. Enzyme was extracted using phosphate buffer $(0.1 \mathrm{M}, \mathrm{pH} 7.0)$ at $1: 5$ (weight/volume) ratio, with a contact time of 30 minutes and agitation at $150 \mathrm{rpm}$ at room temperature on a rotary shaker. Dampened cheese cloth was used to filter the extractant (Nagendra Prabhu, 1997, Nagendra Prabhu Chandrasekaran, 1995, 1996, 1997 \& 1999). After extracting twice, the extracts were pooled and centrifuged at $10000 \mathrm{rpm}$ at $4^{0} \mathrm{C}$ for 15 minutes. The supernatant was assayed for protein (Lowry et. al., 1951) and cellulase (Filter Paper method, Mandels et. al., 1976). The unit of activity $(U)$ is defined as the amount of enzyme liberating I $\mu \mathrm{mol}$ of glucose per minute in a standard assay. The enzyme units were expressed as filter paper units per gram dry substrate (FPU/gds). 


\section{Optimization of process parameters influencing cellulase production}

The protocol adopted for optimizing the process parameters influencing cellulase yield was to optimize one particular parameter and incorporating it at the optimized level in the next experiment (Sandhya and Lonsane, 1994). The parameters analyzed included initial moisture content $(1: 0.2 ; 1: 05 ; 1: 0.75 ; 1: 1 \mathrm{w} / \mathrm{v}$ and no added moisture), initial $\mathrm{pH}$ of the medium ( $\mathrm{pH} 5$ to 9 ), incubation temperature $\left(30^{\circ} \mathrm{C}, 35^{\circ} \mathrm{C}, 40^{\circ} \mathrm{C}\right.$ and $\left.45^{\circ} \mathrm{C}\right)$, fermentation time $(24,36,48,60$ and 72 hours), inoculum concentration $\left(0.1,0.2,0.4,0.6,0.8\right.$ and $\left.1 \mathrm{OD}_{620}\right)$, additional nitrogen sources (urea, ammonium sulphate, peptone and yeast extract - each at $0.1,0.5,1$ and $2 \%$ $\mathrm{w} / \mathrm{w}$ levels) and carbon sources (sucrose and tri-sodium citrate - each at $01,0.5,1$ and $2 \% \mathrm{w} / \mathrm{w}$ levels), in that order. Cellulase production by the three isolates was compared after conducting the fermentation under optimized conditions. All experiments were carried out in triplicate and mean values are reported.

\section{RESULTS}

Our earlier study had resulted in the isolation of several cellulolytic bacteria. Of the three selected isolates, SMB 3 was identified as Alcaligens faecalis and WHB 3 as Aquaspirillum sp. WHB 4 is yet to be identified. The identified cultures have been deposited in MTCC with accession numbers, Alcaligens faecalis MTCC 6198 and Aquaspirillum sp. MTCC 6367.

All the three isolates produced cellulase enzyme by SSF using water hyacinth as the solid support. Enzyme yield showed an increasing trend when the various parameters were optimized. The protein content also increased correspondingly (data not shown). The results of the individual optimization steps are not discussed while the major results obtained are summarized in Figures 1 to 2 and Table 1.

From the results, it is clear that SMB 3 produced cellulase ranging from $16.8 \mathrm{FPU} / \mathrm{gds}$ to $94.8 \mathrm{FPU} / \mathrm{gds}$ when the first set of parameters (added moisture, $\mathrm{pH}$, temperature, incubation time and inoculum concentration) were optimized. Similarly, for WHB 3, the enzyme yield showed an increase from 25.2 FPU/gds to $110.4 \mathrm{FPU} / \mathrm{gds}$ and for WHB 4, it was from $18 \mathrm{FPU} / \mathrm{gds}$ to $127.2 \mathrm{FPU} / \mathrm{gds}$ (Figure 1).

Addition of nitrogen and carbon sources resulted in a significant increase in cellulase yield, as evident from the results shown in Figure 2. When Urea at $1 \%(\mathrm{w} / \mathrm{w})$ level was added, the enzyme yield increased from 94.8 $\mathrm{FPU} / \mathrm{gds}$ to $139.6 \mathrm{FPU} / \mathrm{gds}$ for SMB 3, whereas for WHB 3 , it increased from $110.4 \mathrm{FPU} / \mathrm{gds}$ to $154 \mathrm{FPU} / \mathrm{gds}$ while for WHB 4 the increase was from $127.2 \mathrm{FPU} / \mathrm{gds}$ to 152.8 FPU $/ g d s$. When sucrose at $2 \%(w / w)$ level was added, the cellulase yield increased further (Figure 2). When a comparison of cellulase yield from the three selected bacteria is made, it can be observed that WHB 3 produced the maximum (216 FPU/gds) whereas SMB 3 produced $210 \mathrm{FPU} / \mathrm{gds}$ and WHB 4 yielded $180 \mathrm{FPU} / \mathrm{gds}$ under standardized conditions (Table 1).

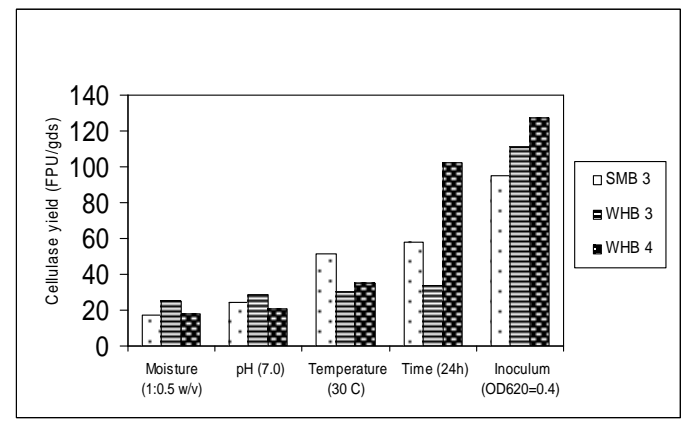

Figure 1: Effect of first set of parameters on cellulase production by the selected isolates

(only enzyme yield at optimum value for each parameter is shown)

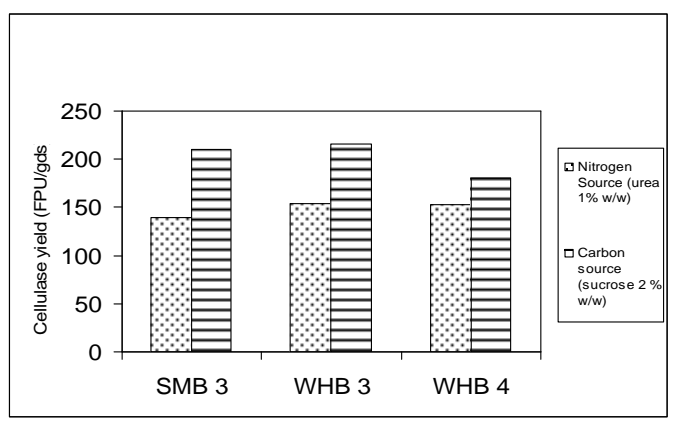

Figure 2: Effect of second set of parameters on cellulase yield by the selected isolates

(only enzyme yield at optimum value for each parameter is shown)

Table 1: Comparison of cellulase production by different bacteria using water hyacinth as substrate under optimized conditions*

\begin{tabular}{cc}
\hline Bacteria & Cellulase yield (FPU/gds) \\
\hline SMB 3 & 210 \\
WHB 3 & 216 \\
WHB 4 & 180
\end{tabular}

${ }^{*} \mathrm{pH}-7,24 \mathrm{~h}, 30^{\circ} \mathrm{C}$, Moisture - 1:0.5 (w/v); Inoculum - $\mathrm{OD}_{620}=$ $0.4 ;$ Sucrose $2 \%(w / w)$ and Urea $1 \%(w / w)$

\section{DISCUSSION}

Large amount of money is wasted by many countries for the removal of the aquatic weeds. Due to their ability for quick vegetative reproduction and production of dormant seeds, the cleared areas are again infested. The only way of successful eradication is by popularizing the concept of utilization. Most of the aquatic weeds can be 
changed into many other useful products, as bio-fertilizer, processed food, biogas, for waste water treatment, for the production of paper and fibre and even as ornamental plants (Gopal, 1987). There are reports that these could be used as materials for mushroom cultivation. Several useful microbial products such as enzymes, organic acids, alcohol etc. can be obtained from these as they can be used as substrates for microbial growth. National Environmental Engineering Research Institute, Nagpur, India had reported that the slurry obtained from aquatic weeds like water hyacinth could be used as a source of cellulose for microbial growth and enzyme production. (Harley et. al., 1997; Nagendra Prabhu, 2001; Calvert, 2002). The results herein revealed the presence of cellulolytic bacteria associated with aquatic weeds like Eichhornia and Salvinia. These plants can be utilized for the production of microbial cellulase, which finds enormous applications in various fields, by the process of SSF (Nagendra Prabhu, 2001; 2002, 2003, 2004). According to Tengerdy (1996) and Tengerdy and Szakacs (2003), SSF may be used advantageously for enzyme production, especially in those agro-biotechnological applications, where the crude fermented product may be used directly as the enzyme source. Thus it offers a good opportunity for countries which produce huge amounts of agro-industrial residues and/or those having biodiversity and biomass.

Successful utilization of cellulosic materials as renewable carbon sources is dependent on the development of economically feasible process technologies for cellulase production, and for the enzymatic hydrolysis of cellulosic materials to low molecular weight products such as hexoses and pentoses. Spano (1978) showed that cellulase production was the most expensive step during ethanol production from cellulosic biomass and that it accounted for approximately $40 \%$ of the total cost. Significant cost reduction is required in order to enhance the commercial viability of cellulase production technology. Hence the commercial use of cellulase is dependent on the following: i) high titer and good enzymatic activity; ii) low production cost, and iii) feasible mass production (Peilin and Liming, 1999). The global market for bio-fuels such as cellulose ethanol is expected to exceed US $\$ 10$ billion by 2012 (logen Corporation, 2004).

Kumar and Singh (2001) reported that Eichhornia biomass could be used as lignocellulosic biopolymer for cellulase and $\beta$-glucosidase production by co-cultivation of $A$. niger and $T$. reesi, under semi solid state fermentation. But the process required lot of pre-treatment steps and is not strictly SSF in nature. Villena et. al., (2001) reported cellulase production by fungal biofilms on polyester cloth. Results of the present study indicate that there is great potential for utilizing this technology for the development of economically viable, eco-friendly and simple technologies that will generate employment opportunities besides producing a range of useful products.

\section{CONCLUSION}

Water is an important resource and infestation of water with aquatic weed is a major global problem. The intensive efforts with different control measures and huge expenditure brought no success in controlling these weeds. Greater attention needs to be focused on finding ways and means for the utilization of these weeds. The present study reveals the presence of cellulase producing microbes associated with these plants which can be tapped for producing useful enzymes like cellulase, by SSF.

This is a basic study on the growth and enzyme production by newly isolated bacteria associated with common aquatic weeds (Eichhornia and Salvinia) which helps to focus attention on the utilization of similar natural resources by suitable biotechnologies. In the long run, appropriate, low-cost and simple solid state fermentation technique using water hyacinth and other aquatic weeds as substrate for the production of cellulase enzyme may be developed. Cellulase production using SSFbioreactors and tray fermentation at both sterile and unsterile conditions is under investigation at the author's laboratory, with a view to scale-up the process and possible commercialization at a later stage. This will result in the economic utilization of water hyacinth and similar aquatic weeds which will help in their control as well as reducing their adverse impact on water bodies. Local level employment can be generated once the technology is commercially viable. Further research in this area will help accelerate the progress in this direction.

\section{ACKNOWLEDGEMENT}

This study was carried out with financial support from the State Committee of Science, Technology and Environment (STEC), Government of Kerala and the Department of Science and Technology (DST), Government of India. Support from the Management of AIMST, Malaysia is also gratefully acknowledged.

\section{REFERENCES}

Bhat, M. K. (2000). Cellulases and related enzymes in Biotechnology. Biotechnology Advances 18: 355-383.

Calvert, P, (2002). Water hyacinth - control and possible uses. Technical Brief. International Technology Development Centre. UK.

Cellulose ethanol is ready to go. (2004). News release, April 21, logen Corporation, Canada.

Evans, D.A. and Bravo, J.E, (1983). Plant protoplast isolation and culture. International Reviews in Cytology (Supplement). 16: 33-53.

Gopal, B. (1987). Water Hyacinth. Aquatic Plant Studies Series. Hindasia publishers. New Delhi.

Harley, L. S., Julien, M. H and Wright A. D. (1997). Water hyacinth: a tropical world wide problem and methods for its control. Proceedings of the first meeting of the International Water Hyacinth Consortium. World Bank. 
Kumar R. and Singh R.P, (2001). Semi-Solid-State Fermentation of Eichhornia crassipes biomass as lignocellulosic biopolymer for cellulase and $\beta$ glucosidase production by co-cultivation of Aspergillus niger RK3 and Trichoderma reesei MTCC164. Applied Biochemistry and Biotechnology. 96(1-3): 71-82.

Lonsane, B. K. (1994). Resurgence of interest in solid state fermentation - reasons and justifications. In. Solid state fermentation. Pandey. A (ed.) Wiley Eastern, New Delhi.

Lowry, O. H., Rosebrough, N. J., Farr, A. L and Randall. R. J. (1951). Protein measurements with the Folin phenol reagent. Journal of Biological Chemistry. 193: 265-275.

Mandels, M., Andreotti, R and Roche. C. (1976). Measurement of saccharifying cellulase. Biotechnology and Bioengineering. 6(2): 1-33.

Nagendra Prabhu, G, (1997). L - Glutaminase production by marine Vibrio costicola under solid state fermentation. Ph. D. Thesis. Cochin University of Science and Technology, Cochin, India.

Nagendra Prabhu. G. (2001). Strategies for economic utilisation of aquatic weeds of Kerala. Proceedings of the National Seminar on Kuttanad Development, Edathua, Alleppey, India, 22-24 November.

Nagendra Prabhu, G. (2002). Optimal utilization of agroindustrial and fishery wastes of Kerala through solid state fermentation. Proceedings of the National Seminar on Biotechnology in Industry, Cochin, India, September 19-20.

Nagendra Prabhu, G, (2003). Solid state fermentation - a suitable biotechnology for the optimal utilization of agro-industrial and fishery wastes of Kerala. South Asian Journal of Socio Political Studies. 3 (2), 103105.

Nagendra Prabhu, G. (2004). Bioconversion of lignocellulosic materials. Everyman's Science. 38(6): 354356.

Nagendra Prabhu, G and Chandrasekaran, M. (1995). Polystyrene - an inert carrier for L-glutaminase production by marine Vibrio costicola under solid state fermentation. World Journal of Microbiology and Biotechnology 11: 683-684.

Nagendra Prabhu, G and Chandrasekaran, M. (1996). L-Glutaminase production by marine Vibrio costicola under solid state fermentation using different substrates. Journal of Marine Biotechnology, 1996, 4: 176-179.

Nagendra Prabhu, G and Chandrasekaran, M. (1997). Impact of process parameters on L-glutaminase production by marine Vibrio costicola in solid state fermentation using polystyrene as an inert support. Process Biochemistry. 32( 4):, 285-289.
Nagendra Prabhu, G and Chandrasekaran, M. (1999). Purification and characterisation of an anticancer enzyme produced by marine Vibrio costicola under a novel solid state fermentation process. Brazilian Archives of Biology and Technology. 42(3): 363-367.

Nigam, P. and Singh. D. (1996). Processing of agricultural wastes in solid state fermentation for cellulolytic enzymes production. Journal of Scientific and Industrial Research. 55: 457-463.

Pandey, A., Soccol. C. R., Rodriguez. L. and Nigam. P. (2001). Solid state fermentation in biotechnology fundamentals and applications. Academic Publishers. New Delhi.

Peilin Cen and Liming Xia, (1999). Production of Cellulase by Solid-State Fermentation. Advances in Biochemical Engineering/Biotechnology. Recent Progress in Bioconversion of Lignocellulosics pp. 69 92.

Potrykus, J. and Shillito, R.D, (1986). Protoplasts: Isolation, culture, plant regeneration. Methods in Enzymology. 118: 549-78.

Sandhya, X and Lonsane, B. K. (1994). Factors influencing fungal degradation of total soluble carbohydrates in sugar cane pressmud under solid state fermentation. Process Biochemistry, 29: 295301.

Snishamol, C., Suresh Chandra Kurup, R. and Nagendra Prabhu, G. (2001). Isolation and preliminary characterization of cellulolytic bacteria associated with common aquatic weeds of Kerala. Annual Conference on Microbial Biotechnology, Association of Microbiologists of India Gulbarga, Karnataka, India. November 9-11.

Spano, L, (1978). Enzymatic hydrolysis of cellulose to fermentable sugar for production of ethanol. In "Proceeding of 2nd Annual Symposium on Fuels from Biomass" Ed. Shuster, W.W., John Willey and Sons, New York. pp. 671-684.

Suresh Chandra Kurup, R. and Nagendra Prabhu, G, (2001). Utilization of water hyacinth for cellulase production using native microflora under SSF. International Conference on New Horizons in Biotechnology, Trivandrum, April 18-21.

Tengerdy, R. P. (1996). Cellulase production by solid substrate fermentation. Journal of Scientific and Industrial Research. 55: 313-316.

Tengerdy, R. P. and Szakacs. G. (2003). Bioconversion of lignocellulose in solid substrate fermentation. Biochemical Engineering Journal. 13: 169-179.

Villena, G. K., Moreno, P. and Gutierrez-Correa, M. (2001). Cellulase production by fungal biofilms on polyester cloth. Agro-food-Industry Hi-Tech. pp. 3235. 